\title{
A ATUALIDADE DE MAX WEBER: ENTREVISTA COM WOLFGANG SCHLUCHTER
}

Tradução de Markus A. Hediger

Wolfgang Schluchter é reconhecido por seus aportes inovadores à compreensão da obra de Max Weber. Professor de Sociologia da Universidade de Heidelberg, dedicou-se durante muitos anos à reconstrução sistemática da obra de Max Weber, com o objetivo de elaborar um paradigma que contribuísse para a discussão da teoria sociológica como alternativa às vertentes contemporâneas - a exemplo da teoria da ação comunicativa ou da teoria dos sistemas. Criou assim um programa de pesquisa interdisciplinar com a participação de teólogos, filósofos, economistas, historiadores e cientistas políticos, estabelecendo um profícuo intercâmbio com colegas estrangeiros. Neste sentido, pôde conhecer a recepção de Max Weber em círculos intelectuais de culturas diversas. Um dos pontos relevantes da investigação de Wolfgang Schluchter, entretanto, são seus estudos da sociologia da religião weberiana, a partir da qual seria possível compreender os processos históricos de racionalização da cultura ocidental moderna. Finalmente, deve-se ao sociólogo, juntamente com outros especialistas, a concepção do projeto da edição crítica completa da obra de Max Weber. Um de seus editores-chefes, Schluchter foi responsável por parte da revisão de Economia e sociedade, que reorganizou o livro de acordo com a ordem cronológica dos escritos originais. A MWG - Max Weber Gesamtausgabe [Max Weber — Edição completa], com certeza, mudará tanto os hábitos de leitura como os rumos da recepção das ideias de Weber. Por sua intensa atividade de pesquisa e relevante contribuição ao entendimento dos projetos weberianos, não há dúvida que Wolfgang Schluchter é um dos sociólogos que melhor pode falar sobre a atualidade do mestre alemão.

Qual é o significado intelectual de Max Weber na sociologia alemã da atualidade? A sociologia alemã, de forma semelhante à sociologia norte-americana, assumiu um foco empírico. O levantamento e a análise de dados relacionados a problemas sociais mais ou menos relevantes dominam o campo. Alguns desses estudos têm orientação teórica, mas existe aqui um ecletismo indulgente. Usa-se o que se acredita precisar, sem reflexão teórica mais aprofundada, e normalmente a história das teorias é em grande parte ignorada. 
O círculo relativamente pequeno daqueles que participam de discussões teóricas cultiva um pluralismo teórico bastante fértil. Podem-se distinguir orientações teóricas fundamentais, ainda que em parte se excluam mutuamente, como, por exemplo, a teoria de sistemas e a teoria da ação, e dentro da teoria da ação a teoria da ação comunicativa; as diferentes abordagens da teoria da escolha racional; e uma sociologia compreensiva estruturalista-individualista. Mas a maioria dos participantes está disposta a ultrapassar limites e elaborar sínteses. O paradigma weberiano, ou o programa de pesquisa weberiano - como prefiro chamá-lo — , é um jogador respeitado e respeitável nesse jogo teórico relativamente aberto. Através do programa de pesquisa weberiano procuramos estabelecer uma terceira sociologia: uma sociologia compreensiva que esteja além de qualquer individualismo metodológico radical e do holismo ou coletivismo metodológico radical, e que reúna uma abordagem de múltiplos níveis com uma abordagem de dois níveis. Chamo isso também de sociologia "kantianizadora", que estende a metafísica dos costumes de Kant de modo histórico-empírico no sentido de sua antropologia, mas sem sociologizá-la. Os níveis dessa sociologia "kantianizadora" resultam dos estados de agregação das configurações sociais (relação, ordem, associação), os dois lados da afinidade eletiva entre correlações de sentido e posições de interesse, culturas e configurações de ordem. Para isso, os Conceitos básicos de sociologia, de Max Weber, continuam sendo a diretriz, em combinação, é claro, com sua sociologia do poder, direito, religião e economia.

\section{Qual é a recepção do projeto Max Weber Gesamtausgabe na Alemanha e em ou- tros países?}

A Max Weber Gesamtausgabe, que já alcançou 37 volumes, é um empreendimento de longo prazo que independe de modas científicas e preferências de recepção. Ela só chegará a um público mais amplo quando os volumes forem disponibilizados em edições de estudo mais acessíveis em termos econômicos. Por causa do seu preço, apenas as bibliotecas conseguem adquirir os volumes originais com seu extenso aparato científico; compradores privados são cada vez mais raros. Por isso, o público científico mais amplo continua a se familiarizar com Weber em primeiro lugar através de suas edições antigas, principalmente os "Ensaios reunidos", publicados ainda por Marianne Weber, os ensaios sobre a "Doutrina da ciência" (título este não escolhido por Weber pessoalmente para seus escritos sobre a lógica e a metodologia das ciências sociais), sobre "Sociologia da religião", "História social e econômica", "Sociologia e política social" e sobre "Política". Esses livros foram disponibilizados pela editora Mohr Siebeck em uma reedição fotomecânica paralelamente à Gesamtausgabe. Sua paginação está indicada na Gesamtausgabe, possibilitando assim uma comparação entre as duas edições. Além dessas, existem ainda muitas edições de A ética protestante e o "espírito" do capitalismo e Economia e sociedade, na maioria das vezes na forma de reedições de textos antigos. Assim, er- 
ros, principalmente erros tipográficos, de datação e também relativos ao contexto histórico das obras, são reproduzidos. Por sinal, a Max Weber Gesamtausgabe tem uma clientela maior apenas na Alemanha e no Japão. Em outros países, não existem compradores, ou, se existem, apenas em número muito reduzido. Nos Estados Unidos, apesar das muitas bibliotecas, só existem dez, e na França são menos de cinco, para citar apenas alguns exemplos. Exceções são, dado o tamanho desses países, a Suíça, Áustria e Itália. Mas também aqui o número de vendas é baixo.

Não podemos afirmar que a Max Weber Gesamtausgabe tenha estimulado novos projetos de pesquisa. Mesmo em artigos de autores alemães, publicados em revistas ou antologias, não são citados os textos editados na Gesamtausgabe, mas sim os textos antigos. Até agora também não foi publicada nenhuma biografia de Weber que pudesse ser levada a sério. Mas qualquer biografia bem-sucedida só poderá ser escrita após a publicação da Gesamtausgabe completa, baseandose principalmente nas cartas, nas notas de aulas e nas transcrições destas, como também nas correções da história das obras, disponibilizadas nos volumes editados. Essa biografia precisaria retraçar as linhas de desenvolvimento da vida de Max Weber na história contemporânea, na história de suas obras e em sua sistemática através da obra completa do autor, e correlacioná-las com uma grande habilidade para evitar qualquer reducionismo, sejam seus motivos de natureza psicanalítica (Mitzman), nietzscheniana (Green) ou até mesmo naturalista. O grande estudo de Guenther Roth ilumina o contexto familiar (a história da família anglo-alemã de Max Weber de 1800 a 1850), mas não coloca Max Weber no centro de seu interesse. Esse livro, portanto, não substitui uma biografia. A melhor biografia continua sendo Lebensbild [Max Weber: uma biografia] de Marianne Weber, publicada em 1926 (Max Weber: Ein Lebensbild). Se complementássemos as citações de suas cartas, em parte distorcidas, e retirássemos do texto seu estilo heroicizador, ainda teríamos uma obra que superaria claramente todas as outras tentativas existentes de apresentar uma biografia ou até mesmo uma história de suas obras biograficamente fundamentada. Duvido que exista alguém capaz de satisfazer as altas exigências de uma biografia válida. Além do mais, as cartas da sua fase inicial ainda não foram editadas. Tentativas de reduzir a obra de Weber à sua doença ou até mesmo aos seus relacionamentos com mulheres - com Helene Weber, Marianne Weber, Mina Tobler e Else Jaffé — existem, obviamente.

Aparentemente a atualidade de Max Weber nas ciências sociais anglo-saxônicas é diferente de sua recepção na Alemanha, em países europeus e na América Latina. Julga-se que há um declínio de interesse e também de competências na obra de Weber, tanto nos Estados Unidos como na Inglaterra. Como o senhor avalia a posição da sociologia weberiana nesses países?

Apesar da atuação de Talcott Parsons, Reinhard Bendix e Guenther Roth, a recepção de Weber nos Estados Unidos tem sido bem seletiva. Os textos lidos pelos sociólogos normalmente se reduziam à seleção de textos de Hans Gerth 
e Wright Mills (publicada como From Max Weber: Essays in Sociology). Não é por acaso que Reinhard Bendix escreveu seu livro Max Weber: an Intellectual Portrait para familiarizar os estudantes com a sociologia material de Max Weber, em particular com sua sociologia do poder e da religião. Mas, significativamente, deixou a metodologia completamente de fora. Também a exemplar versão em língua inglesa de Guenther Roth e Claus Wittich de Economy and Society, mesmo que baseada em conhecimentos antigos, não pôde mudar nada em relação a essa recepção seletiva (retornaremos a esse ponto). A maioria dos norte-americanos que escrevem sobre Weber não o lê no original. É claro que aqui também existem exceções: cito apenas como exemplos os pesquisadores de Weber Guy Oaks, Steven Kahlberg e Lawrence Scaff. Interessante é também a tentativa de Richard Swedberg de decifrar a sociologia weberiana a partir da sociologia econômica, para a qual hoje já precisariam ser consultadas suas aulas da fase inicial, em especial aquelas sobre a "Economia nacional geral ('teórica')". O dicionário da sociologia weberiana em inglês, de Swedberg (Max Weber Dictionary: Key Words and Central Concepts), não trouxe novos estímulos para a recepção de Weber nos Estados Unidos, apesar da inegável utilidade dessas tentativas de transferência.

Na Inglaterra, Marx sempre foi mais importante do que Weber. Ao menos, parece que partes da obra weberiana tenham servido como building block para a teoria de estruturação de Anthony Giddens. E também a abordagem importante de Margaret Archer parece ser influenciada por Weber. Além disso, existe um grupo que se reúne em torno dos WeberStudies. Mas sua importância para a elaboração teórica e o desenvolvimento da matéria é marginal.

A Sociologia mudou o seu perfil a partir dos anos 1970, quando interesses políticos e econômicos também mudaram. A disciplina se voltou de modo destacado para a sua própria história, sua identidade cognitiva, seus paradigmas e quadros teóricos e conceituais, assim como passou a se interessar pelas implicações do processo peculiar de sua institucionalização. $O$ senhor acha que a orientação histórica é atualmente proeminente nos estudos sobre Max Weber, ou a dimensão teórica e conceitual de sua obra ainda pode contribuir para o entendimento do mundo capitalista de hoje?

É claro que desenvolvimentos intelectuais não são imunes a mudanças econômicas e políticas. Mas a relação não é tão íntima quanto sugere a sua pergunta. Na década de 1970, a recepção de Weber na Alemanha de fato sofreu uma mudança significativa, mas esta se devia mais ao declínio do pensamento marxista, que até então exercia grande influência sobre a sociologia. Nas décadas de 1950 e 1960, a recepção se limitava principalmente a Max Weber como político (Mommsen) e como metodologista (escola de Popper, Albert), e os marxistas o consideravam o apologista de um capitalismo fadado à falência (Lukács, Marcuse e, de certo modo, também a Escola de Frankfurt mais antiga). Mas, nas dé- 
cadas de 1970 e 1980, o foco se voltou para a sociologia da religião; não, porém, para sua série de ensaios sobre o protestantismo ascético, mas sim para seus estudos comparativos sobre a ética econômica das religiões mundiais. Nisso, o trabalho conceitual conquistou o primeiro plano. A consequência disso também foi que o duro conflito entre os weberianos e os representantes da teoria crítica, que existiu por muito tempo, começou a se dissolver visivelmente. A teoria da ação comunicativa, de Jürgen Habermas, projeta uma imagem de Weber completamente diferente se comparada com a da escola de Frankfurt mais antiga.

Mas também pode-se dizer que, após a norte-americanização da sociologia alemã nas décadas de 1950 e 1960, a disciplina começou a se lembrar de suas próprias raízes durante as décadas de 1970 e 1980. Isso também estimulou a recepção de Weber. Ao mesmo tempo, foram retomados outros instrumentais conceituais da sociologia alemã mais antiga. Deu-se início à recepção de Norbert Elias, de Georg Simmel e também, em escala menor, de Ferdinand Tönnies. Juntou-se a isso a radicalização da teoria de sistemas por Niklas Luhmann e finalmente a abertura da sociologia alemã para a sociologia francesa - mas não vice-versa. Nessa fase, a sociologia weberiana ocupou um papel importante. Desde então, essa importância tem diminuído.

A ideia central de racionalidade que orienta a explicação compreensiva do mundo capitalista tem sido questionada. Segundo Guenther Roth (2005: 40), "A sociologia econômica de Weber pode ser utilizada, particularmente, se deslocarmos a atenção de sua história do desenvolvimento do racionalismo para sua tipologia de diferentes formas de capitalismo e examinarmos os modos nos quais o capitalismo 'moderno' está desatualizado". A racionalidade enquanto valor que orienta a ação em diversas dimensões da vida social ainda tem valor heurístico?

Desde 1910-11, a ideia condutora de Weber tem sido o processo de racionalização, principalmente sob a perspectiva de seu significado para o desenvolvimento específico ocidental. Como se sabe, ela lhe veio durante sua ocupação com a teoria da música. A meu ver, essa ideia condutora continua sendo diretiva; pelo menos é mais produtiva em termos analíticos do que a da globalização. Ao mesmo tempo, Weber reconhece o paradoxo da racionalização, ou seja, que ela sempre produz também o seu oposto. Essa averiguação não representa uma contradição à afirmação de Guenther Roth citada acima, já que uma tipologia do racionalismo é condição necessária para quem deseja entender a história do desenvolvimento desse conceito. E o que vale para o racionalismo, vale também para o capitalismo, cuja tipologia se encontra desenvolvida na nova versão de Economia e sociedade no segundo capítulo. Como sabemos, Weber diferencia entre o capitalismo orientado pelo poder e o capitalismo orientado pelo mercado, e, dentro deste, entre o capitalismo de oportunidade e o capitalismo comercial industrializado. E esses não são os únicos "capitalismos" dos quais ele fala em sua obra. Para ele, o capitalismo é, diferentemente de Marx, 
um fenômeno histórico-universal, que remete até a Antiguidade. Hoje, estudam-se varieties of capitalism, mas, na maioria das vezes, sem referência a Weber. Mas para a compreensão do capitalismo na Rússia e na China as distinções estabelecidas por Weber ainda podem ser úteis.

Uma questão cara a Max Weber foi a ética das ações humanas. A ética da convicção e a ética da responsabilidade podem ainda servir de orientação para as ações humanas em um mundo avesso ao ascetismo e ao individualismo humanista?

O ideal de personalidade de Max Weber certamente era o de um individualismo ascético e espiritual-aristocrático. Mas isso é uma posição de valor que precisa ser distinguida de suas análises histórico-empíricas. O ser humano, que assume uma posição, que avalia e julga, que vive suas ideias e seus ideais, e o pesquisador empírico, que estuda o efeito desses ideais e ideias vividos, agem em esferas diferentes, na esfera do prestígio, como Weber às vezes dizia, e na esfera das relações fatuais, ambas interligadas através da teoria da relação de valor. A distinção entre ética da convicção e ética da responsabilidade, à qual sua pergunta alude, pertence a esse contexto duplo. Em primeiro lugar, deveríamos evitar um equívoco terminológico aparente: a ética da convição não é equivalente a irresponsabilidade, e a ética da responsabilidade não significa falta de convicção. A questão é: por que devo assumir responsabilidade? Assume-se responsabilidade apenas por uma convicção pura e honesta, ou, além disso, também pelas consequências previsíveis relacionadas à realização dessa convicção pura? A correlação normalmente estabelecida entre a ética da convicção e a racionalidade de valores e entre a ética da responsabilidade e a racionalidade de propósitos é completamente infundada. Ambas são fundamentadas na racionalidade de valores, mas a ética da responsabilidade amplia seu âmbito de responsabilidade. Acredito que, como ser humano que assumia posições e que avaliava e julgava, Weber tenha defendido a ética da responsabilidade. Mas, como pesquisador empírico, ele se interessava principalmente pelos efeitos da ética da convicção, tanto no âmbito religioso quanto no político. Mas uma ação que se orienta por máximas morais sempre corre perigo de ser suplantada por uma ação que se orienta por outras máximas, por exemplo, por máximas de utilidade. Isso independe completamente da situação histórica.

Weber dedicou parte relevante de seus estudos às religiões. Demonstrou que a secularização, característica do capitalismo moderno, se inicia, justamente, com a Reforma Protestante, não sendo possível portanto separar a esfera secular da esfera religiosa. A atual importância individual das crenças religiosas e a explosão coletiva de conflitos de ordem religiosa e política comprovam que Weber acertou no que concerne à permanência das crenças religiosas na vida social secularizada? Ao contrário da crítica de religião do século XIX — de, por exemplo, Feuerbach e Marx -, Weber reconheceu o potencial de racionalidade das religiões, em 
particular das por ele assim chamadas religiões de salvação. Em algumas manifestações individuais dessas religiões de salvação, Weber identificou agentes de racionalização da cultura moderna (o judaísmo antigo e o protestantismo ascético). A meu ver, a secularização é entendida de forma errada se interpretada como o desaparecimento da fé em Deus nos indivíduos. Esta, pelo menos, não era a posição de Weber quando tratava da secularização. Ele pensava muito mais no estado de uma configuração de ordem moderna e, especificamente, na posição da ordem religiosa em relação aos outros poderes e ordens sociais. Religião e política, igreja e Estado representavam para ele na cultura moderna entidades relativamente autônomas e separadas uma da outra. O direito secular reina sobre o direito religioso, e não o religioso sobre o secular. E o direito secular também não mais é fundamentado no direito natural. O período confessional com suas guerras religiosas, durante as quais foi conquistada essa separação para o Ocidente, provou ser um importante promotor da racionalização moderna. É claro que isso não significa que lutas políticas com motivos religiosos tenham se tornado impossíveis de uma vez por todas. Basta ler o fim da Ética protestante, onde Weber fala de um possível renascimento de antigas ideias e ideais.

Finalmente, gostaria de lhe fazer uma pergunta sobre a recepção de Weber no Brasil. Os sociólogos brasileiros leram Economia e sociedade de Max Weber em espanhol, dado o grande empreendimento da editora mexicana Fondo de Cultura Económica que publicou o livro com tradução de Medina Echevarria, em 1944. Leram A ética protestante e o "espírito" do capitalismo primeiro na tradução de Talcott Parsons. $O$ estudo de Weber, obrigatório em cursos de graduação e pósgraduação, se faz ainda pela orientação e interpretação norte-americana, embora tenhamos traduções de obras diretamente do alemão, como Economia e sociedade. Existe entre os editores e especialistas em Weber algum interesse em tornar a Max Weber Gesamtausgabe mais acessível aos leitores brasileiros (e outros) que não têm o domínio do idioma alemão?

Os trabalhos no contexto da Max Weber Gesamtausgabe esclarecem de uma vez por todas que Economia e sociedade não é um livro em três (Marianne Weber) ou duas (Johannes Winckelmann) partes, mas sim um projeto em duas versões, das quais a mais antiga foi escrita antes da Primeira Guerra Mundial; e a nova, depois. A nova versão se baseia na antiga, mas apresenta novos termos básicos e também uma sociologia da economia que aparentemente não fazia parte da versão antiga. Já em relação à sociologia do poder e ao capítulo iniciado sobre "Estamentos e classes", o caso é diferente, pois esses representam condensações dos manuscritos pré-guerra. Por isso, seria muito bom se fosse feita uma nova tradução que respeitasse esses fatos também na ordenação dos textos. Mas isso seria um empreendimento tremendo, que não sei se é possível realizar. 
A situação é parecida em relação ao conjunto de ensaios em A ética protestante e o "espírito" do capitalismo. Aqui, é preciso lembrar em primeiro lugar que existem duas versões desse texto (de 1904-05 e de 1919-20). A primeira versão contém muitos erros, porque o tipógrafo nem sempre conseguiu decifrar a letra de Weber. Muitos desses erros tipográficos, inclusive muitas referências às páginas das fontes citadas, permaneceram. Weber não as corrigiu na segunda versão de 1919-20. Nesta, ele se preocupou mais com a ampliação do que com a correção do texto antigo. Portanto, seria prudente esperar que seja publicada a nova edição pela Max Weber Gesamtausgabe para fazer uma tradução. Além disso, deveriam ser levadas ao conhecimento do público as explicações de Weber sobre as seitas e sua discussão com seus críticos. Na edição em língua inglesa, publicada por Steven Kahlberg, isso foi feito pelo menos de forma rudimentar, mas sem que as diferenças entre as duas versões tivessem sido assinaladas (The Protestant Ethic and the Spirit of Capitalism: the Revised 1920 Edition). Além do mais, está incluído nessa coleção o último capítulo das aulas de Weber do semestre de inverno de 1919-20 sobre "A história social e econômica universal", que não representa um texto original de Weber, mas que foi reconstruído a partir de transcrições após sua morte. Enquanto não existir nenhuma tradução nova em português ou espanhol, sugiro que nas aulas seja usada essa edição, e não a de Talcott Parsons. É claro que a leitura do original é sempre a melhor opção.

A tradução de partes da Gesamtausgabe para várias línguas já começou. Alguns textos ou até volumes já foram traduzidos para o japonês, coreano, inglês, italiano e francês. Na Itália, já foram publicados três volumes da antiga versão de Economia e sociedade. Na França, foi publicado o estudo sobre o confucionismo graças à iniciativa de Pierre Grossein, que lamenta justificadamente o fato de a recepção de Weber na França ser prejudicada pela falta de qualidade das traduções disponíveis. O que vale para a França vale também para muitos outros países. É difícil prever o desenvolvimento no futuro. Mais recentemente, até mesmo uma editora árabe demonstrou interesse pela tradução de textos da Gesamtausgabe. A impressão que temos não é homogênea e é difícil oferecer um prognóstico. Talvez o interesse por Max Weber passe a ser maior nos países emergentes, porque lá estão sendo iniciados processos de racionalização que podem ser analisados com seus instrumentos conceituais. É, portanto, bastante improvável que o programa de pesquisa weberiano desapareça da agenda sociológica no futuro próximo. 


\section{REFERÊNCIA BIBLIOGRÁFICA:}

Roth, Guenther. Max Weber, Scion of the Cosmopolitan Bourgeoisie: Historical Context and Present-Day Relevance. In: Camic, Charles; Gorski, Philip \& Trubek, David (orgs.). Max Weber's Economy and Society: a Critical Companion. Stanford: Stanford University Press, 2005, p. 31-46.

Glaucia Villas Bôas é professora do Departamento de Sociologia e do Programa de Pós-Graduação em Sociologia e Antropologia do Instituto de Filosofia e Ciências Sociais (IFCS) da Universidade Federal do Rio de Janeiro (UFRJ). É autora de A recepção da sociologia alemã no Brasil (2006); Mudança provocada: passado e futuro no pensamento sociológico brasileiro (2006) e A vocação das ciências sociais: um estudo de sua produção em liuros do acervo da Biblioteca Nacional (2007). É pesquisadora do Conselho Nacional de Desenvolvimento Científico e Tecnológico (CNPq) e coordena o Núcleo de Pesquisa em Sociologia da Cultura, onde desenvolve atualmente projetos de pesquisa sobre arte e sociedade e história da sociologia no Brasil. 
Resumo:

O ousado projeto de publicação das obras completas de Max Weber, que vem sendo realizado desde 1976 sob a coordenação de renomados sociólogos alemães, motiva esta entrevista com Wolfgang Schluchter, um dos editores-chefes da MWG - Max Weber Gesamtausgabe [Max Weber - Edição completa]. A entrevista tem o objetivo de indagar sobre a atualidade do instrumental teórico e conceitual do sociólogo alemão. Qual é a repercussão hoje das hipóteses weberianas sobre a sociedade capitalista, nos círculos acadêmicos e intelectuais? Em que medida a edição crítica e histórica das obras completas de Max Weber contribui para estimular novas linhas de investigação no campo da sociologia? Para Schluchter, o projeto da edição crítica não é afeito a modas ou preferências intelectuais passageiras. Considera que, apesar das atuais limitações da discussão teórica em favor da empiria, é pouco provável que a contribuição de Weber quanto aos processos de racionalização desapareça do horizonte sociológico.

Abstract: The bold project of publishing the complete works of Max Weber, that has been held since 1976 under the direction of renowned German sociologists, motivates this interview with Wolfgang Schluchter, one of the head editors of MWG - Max Weber Gesamtausgabe [Max Weber - complete edition]. The interview aims to inquire about the current character of conceptual and theoretical tools of the German sociologist. What is the impact today of Weber's assumptions about the capitalist society on the academic and intellectual circles? To what extent the historical and critical edition of the complete works of Max Weber helps to stimulate new research issues in the field of sociology? To Schluchter, the critical edition project is not connected to intellectual fashions or fleeting preferences. He considers that, despite the limitations of the theoretical discussion in favor of empiricism, it is unlikely that the contribution of Weber regarding rationalization processes disappear from the sociological horizon.

\section{Palavras-chave:}

Max Weber; Atualidade de Max Weber; Edição da obra completa de Max Weber; Wolfgang Schluchter; Recepção da sociologia de Max Weber.

Keywords:

Max Weber; Current

relevance of Max Weber; Complete edition of Max Weber's works; Wolfgang Schluchter; Reception of Max Weber's sociology. 